'Laboratôrio de Tecnologia de Bioativos, Universidade Federal Rural de Pernambuco, Rua Dom Manuel de Medeiros, s/n, CEP 52171-900, Recife, PE, Brasil

2Instituto Agronômico de Pernambuco, Bongi, Recife, PE, Brasil

${ }^{3}$ Universidade de Pernambuco, Santo

Amaro, Recife, PE, Brasil

*autor correspondente liviasfreittas36@gmail.com

\title{
Uso de substratos agroindustriais para produção de delta-endotoxinas por Bacillus thuringiensis
}

\author{
Use of agro-industrial substrates for delta-endotoxins \\ production by Bacillus thuringiensis
}

Lívia Santos de Freitas ${ }^{*}$, José Manoel Wanderley Duarte Neto². Túlio Alexandre Freire da Silva' Caroline Fernanda Bezerra de Oliveira' ${ }^{1}$, Débora Pessoa de Oliveira' ${ }^{1}$, Daniela de Araújo Viana Marques $^{3}$, Raquel Pedrosa Bezerra ${ }^{1}$, Ana Lúcia Figueiredo Porto'

RESUMO: Este trabalho teve o objetivo de avaliar o crescimento e a produção de delta-endotoxinas, esporos e proteases por Bacillus thuringiensis var. berliner, utilizando substratos agroindustriais de palma forrageira (Opuntia), xarope de sorgo (Sorghum) ou soro de leite, com ou sem suplementação de ureia $1 \mathrm{~g} / \mathrm{L}$. Luria-Bertani foi utilizado como meio de cultura controle. Culturas de $B$. thuringiensis foram cultivadas em frascos Erlenmeyer incubados em agitador rotativo a $200 \mathrm{rpm}, 30^{\circ} \mathrm{C}$, por 96 horas. Maior crescimento celular $\left(4,28 \mathrm{~g} . \mathrm{L}^{-1}\right)$, produção de delta-endotoxinas $\left(568,26 \mathrm{mg} . \mathrm{L}^{-1}\right)$ e esporos $\left(9,61 \times 10^{10} \mathrm{UFC} \cdot \mathrm{mL}^{-1}\right)$, superiores inclusive ao meio de controle, foram observados ao se utilizar o soro de leite sem ureia. Não se verificou relação direta entre a esporulação e a produção de delta-endotoxinas pelo Btb370 nos meios de cultura, como também entre a produção de proteases e de delta-endotoxinas. A suplementação com ureia 1 g. $\mathrm{L}^{-1}$ foi viável para o substrato palma forrageira na atividade proteásica e para o xarope de sorgo em praticamente todas as análises, contudo não influenciou positivamente o soro de leite. Por meio de microscópio eletrônico de varredura, observou-se a predominância de cristais com morfologias bipiramidal, esférica e cuboidal. Portanto, os resultados sugerem o soro de leite como substrato mais eficiente para novas formulações de meios de cultura para produção de delta-endotoxinas por Bacillus thuringiensis var. berliner, superando os resultados do meio padrão Luria-Bertani.

PALAVRAS-CHAVE: Meio de cultura alternativo, biocontrolador, palma forrageira, xarope de sorgo, soro de leite.
ABSTRACT: This work aimed to evaluate the growth and production of delta-endotoxins, spores and proteases by Bacillus thuringiensis var. berliner, using agro-industrial substrates of forage palm (Opuntia), sorghum syrup (Sorghum) or whey, with or without supplementation of $1 \mathrm{~g} / \mathrm{L}$ urea. Luria-Bertani was used as control culture medium. $B$. thuringiensis cultures were grown in Erlenmeyer flasks incubated on a rotary shaker at $200 \mathrm{rpm}, 30^{\circ} \mathrm{C}$ for 96 hours. The highest cell growth $\left(4.28 \mathrm{~g} \cdot \mathrm{L}^{-1}\right)$, production of delta-endotoxins (568.26 mg. $\left.L^{-1}\right)$ and spores (9.61 $\left.\times 10^{10} \mathrm{CFU} \cdot \mathrm{mL}^{-1}\right)$, even higher than the control medium, were observed using whey without urea. There was no direct relationship between sporulation and delta-endotoxins production for Btb370 in the culture media, as well as between proteases and delta-endotoxins production. Supplementation with urea 1 g. $L^{-1}$ was viable for palm forage substrate in protease activity and for sorghum syrup in practically all analyzes, however it did not positively influence whey. Through the scanning electron microscope, a predominance of crystals with bipyramidal, spherical and cuboidal morphologies could be observed. Therefore, results suggest whey as the most efficient substrate for new culture media formulations for production of delta-endotoxins by Bacillus thuringiensis var. berliner, surpassing the standard Luria-Bertani medium results.

KEYWORDS: Alternative culture medium, biocontroller, forage palm, sorghum syrup, whey.

\section{Introdução}

A bactéria Gram-positiva Bacillus thuringiensis (Bt) é um agente de controle biológico utilizado mundialmente 
para formulações de biopesticidas. É conhecida por sua alta atividade inseticida derivada de proteínas de cristal, geralmente produzidas durante a esporulação e compostas, principalmente, de delta-endotoxinas (RAYMOND et al., 2010). Entre as vantagens de seu uso como biocontrolador, destacam-se: não liberação de resíduos poluentes; segurança para organismos não-alvo; inocuidade para plantas, animais e humanos; alta especificidade para insetos de várias ordens, como Lepidoptera, Diptera e Coleoptera (ADANG et al., 2014; PAN et al., 2017; SCHNEPF et al., 1998).

Além da importância industrial das endotoxinas e dos esporos de Bt na produção de biocontroladores, as proteases obtidas do gênero Bacillus representam aproximadamente $60 \%$ do total das vendas mundiais de enzimas e têm características notáveis para muitas aplicações industriais, como: na indústria de detergentes para a remoção de manchas de tecidos, devido à sua ampla faixa de atividade e à estabilidade de $\mathrm{pH}$ e temperatura; na indústria de alimentos para obter peptídeos bioativos e processar diferentes alimentos; na aplicação durante sínteses orgânicas, por possuírem estabilidade em solventes orgânicos (ANNAMALAI et al., 2013; BOUGATEF et al., 2012; OZCAN; KURDAL, 2012; CAILLE et al., 2002).

Meios de cultura econômicos para a produção de deltaendotoxinas por $B$. thuringiensis têm sido avaliados, uma vez que o uso de substratos comerciais geralmente encarece o preço final dos produtos à base de $\mathrm{Bt} \mathrm{e}$, consequentemente, reduz sua capacidade competitiva contra inseticidas químicos. A exemplo de potenciais substratos alternativos para cultivo de microrganismos, têm-se a palma forrageira (Opuntia), o xarope de sorgo (Sorghum) e o soro de leite, que se caracterizam por serem produtos encontrados abundantemente e que podem ser facilmente adquiridos por preço reduzido na região Nordeste do Brasil.

A palma forrageira constituiu a base alimentar de rebanhos da região Nordeste brasileira, possui baixo teor de proteínas e altos níveis de carboidratos totais, matéria mineral e umidade (FROTA et al., 2015). O xarope de sorgo é composto principalmente de sacarose e minerais, como magnésio, potássio e manganês (RATNAVATHI et al., 2016). O soro de leite é caracterizado por reter cerca de $55 \%$ dos nutrientes do leite durante a produção de queijo, incluindo lactose, proteínas solúveis e sais minerais (FOX et al., 2017).

Em muitos casos, o substrato para cultivo de Bt carece de fonte natural de nitrogênio suficiente para uma boa produção de endotoxinas e há, então, a necessidade de suplementação destas. Possíveis fontes de nitrogênio que podem ser utilizadas para esse fim são glutamato, ureia, farinha de soja, farelo de algodão, peptona, sulfato de amônio, nitrato de potássio, entre outras. Entre estas, a ureia $\left[\mathrm{CO}\left(\mathrm{NH}_{2}\right)_{2}\right]$ é caracterizada por possuir elevada concentração de nitrogênio (45\%), baixo custo e alta solubilidade (MELGAR et al., 1999).

Devido à presença de nutrientes necessários à fermentação de $B$. thuringiensis, aliados à alta disponibilidade e ao baixo custo, a palma forrageira, o xarope de sorgo e o soro de leite foram selecionados para o estudo. Portanto, o objetivo deste trabalho foi avaliar o uso desses substratos no desenvolvimento de novos meios de cultura para crescimento e produção de delta-endotoxinas, esporos e proteases por Bacillus thuringiensis var. berliner, bem como estudar o padrão de cristais produzidos usando microscopia eletrônica de varredura.

\section{Material e métodos}

\section{Microrganismo}

Bacillus thuringiensis var. berliner 370 (Btb370) (cepa: Bt 370; SisGen n ${ }^{\circ}$ AAC4727) foi adquirido da coleção de culturas do Departamento de Antibióticos da Universidade Federal de Pernambuco (Recife, Pernambuco, Brasil). A cepa foi cultivada e mantida em meio Luria-Bertani (LB) composto de peptona 10 g.L. ${ }^{-1}, \mathrm{NaCl} 10$ g.L $\mathrm{L}^{-1}$, extrato de levedura 5 g.L $\mathrm{L}^{-1}$ e ágar 15 g. $\mathrm{L}^{-1}$, incubado a $30^{\circ} \mathrm{C}$, por 24 horas, e armazenado a $-20^{\circ} \mathrm{C}$.

\section{Meios de cultura}

O extrato de palma forrageira (Opuntia), o xarope de sorgo (Sorghum) e o soro de leite foram utilizados como substratos para os meios de cultura alternativos e receberam a adição de ureia 1 g.L $\mathrm{L}^{-1}$. Os meios de cultura foram denominados: PM (extrato de palma forrageira), PUM (extrato de palma forrageira com ureia 1 g. $\mathrm{L}^{-1}$ ), SM (xarope de sorgo), SUM (xarope de sorgo com ureia 1 g. $\mathrm{L}^{-1}$ ), WM (soro de leite) e WUM (soro de leite com ureia 1 g. $\mathrm{L}^{-1}$ ). Todos os meios alternativos receberam a adição de solução mineral composta de 20,3 g.L $\mathrm{L}^{-1}$ de $\mathrm{MgCl}$, 10,2 g.L $\mathrm{L}^{-1}$ de $\mathrm{CaCl} 2$ e 1,0 g.L $\mathrm{L}^{-1}$ de $\mathrm{MnCl} 2$ (SHOJAADDINI et al., 2010). O meio LB líquido foi utilizado como meio controle.

Os cladódios maduros da palma forrageira e o xarope de sorgo foram obtidos do Instituto Agronômico de Pernambuco (Estação Experimental de Arcoverde, Pernambuco, Brasil). $\mathrm{O}$ extrato de palma forrageira foi preparado por trituração dos cladódios de palma em água destilada, previamente sanitizados com hipoclorito de sódio a $2 \%$ por 20 segundos. O extrato de palma e o xarope de sorgo foram diluídos 1:5 em água destilada e autoclavados a $121^{\circ} \mathrm{C}$ por 15 minutos. $\mathrm{O}$ soro de leite foi obtido de uma indústria de laticínios localizada em Garanhuns (Pernambuco, Brasil). O soro teve o $\mathrm{pH}$ ajustado para 7,0 e foi autoclavado a $121^{\circ} \mathrm{C}$ por 15 minutos. Após a esterilização, quando os coágulos são formados, o soro foi filtrado a vácuo dentro de uma capela de laboratório e o sobrenadante foi utilizado como meio de cultura.

\section{Condições de cultivo}

O pré-inóculo foi preparado com Btb370 cultivado em meio LB e incubado em agitador rotativo a $30{ }^{\circ} \mathrm{C}$ e $200 \mathrm{rpm}$, overnight. A preparação do inóculo foi realizada em frascos Erlenmeyer de $125 \mathrm{~mL}$ contendo $20 \mathrm{~mL}$ de meio de cultura com absorbância inicial de 0,15 a $600 \mathrm{~nm}$ (ELLEUCH et al., 2015) para cada meio (PM, PUM, SM, SUM, WM, WUM e LB) e incubado em agitador rotativo a $30{ }^{\circ} \mathrm{C}$ e $200 \mathrm{rpm}$ por 96 horas. Todos os meios de cultura do inóculo foram realizados em duplicatas. Amostras das culturas incubadas foram coletadas diariamente, para observação do crescimento celular, da formação de delta-endotoxinas e esporos e da atividade proteásica de Btb370. 


\section{Determinação da concentração celular}

A concentração celular foi determinada por densidade óptica (D.O) a $600 \mathrm{~nm}$ e massa celular seca, na qual as amostras foram centrifugadas a $10.000 \mathrm{rpm}$ por 10 minutos, os sobrenadantes foram descartados e os precipitados celulares foram incubados a $30^{\circ} \mathrm{C}$ até peso constante. $\mathrm{O}$ peso seco da biomassa foi obtido e expresso em gramas por litro (g.L $\left.\mathrm{L}^{-1}\right)$ (SHOJAADDINI et al., 2010).

\section{Quantificação de delta-endotoxinas}

A concentração de delta-endotoxinas foi determinada com base em uma preparação de cristal solubilizado de cada meio de cultura, de acordo com Prabakaran e Balaraman (2006). Para tanto, foi centrifugado $1 \mathrm{~mL}$ de cada meio a $10.000 \mathrm{rpm}$ por $10 \mathrm{~min}$ e o precipitado resultante foi lavado duas vezes com $\mathrm{NaCl}\left(1 \mathrm{~mol} . \mathrm{L}^{-1}\right)$, duas vezes com água destilada e centrifugado após cada lavagem. Em seguida, o precipitado foi, então, ressuspendido em $1 \mathrm{~mL}$ de $\mathrm{NaOH}\left(50\right.$ mmol. $\left.\mathrm{L}^{-1}\right)$, a fim de solubilizar os cristais de delta-endotoxinas. Por fim, a quantificação proteica foi feita utilizando o Kit BCA (Pierce BCA Protein Assay, Thermo Fisher Scientific, Massachusetts, EUA) e os resultados foram expressos em mg. $\mathrm{L}^{-1}$.

\section{Quantificação de esporos}

As amostras dos meios de cultura foram tratadas termicamente a $80^{\circ} \mathrm{C}$, por 15 minutos, diluídas em série e semeadas em placas com meio ágar LB. As placas foram incubadas a $37^{\circ} \mathrm{C}$ por 20 horas e as colônias Btb370 desenvolvidas foram contadas e expressas em UFC (unidade formadora de colônias) por $\mathrm{mL}$ (SHOJAADDINI et al., 2010).

\section{Atividade proteásica}

A atividade proteásica foi realizada pelo método descrito por Alencar et al. (2003), no qual as amostras do sobrenadante dos meios de cultura foram incubadas com $1 \%(\mathrm{p} / \mathrm{v})$ de azocaseína por 60 minutos a $25^{\circ} \mathrm{C}$, a reação foi interrompida com a adição de $10 \%(\mathrm{p} / \mathrm{v})$ de ácido tricloroacético (TCA) e, após 15 minutos, as amostras foram centrifugadas a $10.000 \mathrm{rpm}$ por cinco minutos. Os sobrenadantes foram coletados e adicionados a uma solução de $\mathrm{NaOH} 1 \mathrm{M}$ em placa ELISA e a absorbância foi medida em um leitor ELISA (iMark ${ }^{\mathrm{TM}}$ Microplate Absorbance Reader, Bio-rad, São Paulo, Brasil) a $450 \mathrm{~nm}$. Os resultados foram expressos em U.mL ${ }^{-1}$, no qual $1 \mathrm{U}$ representa a quantidade de enzima capaz de hidrolisar a azocaseína, proporcionando um aumento de 0,001 unidade de absorbância por minuto.

\section{Caracterização morfológica por microscopia eletrônica de varredura (MEV)}

As amostras dos meios de cultura foram centrifugadas a $10.000 \mathrm{rpm}$, por dez minutos, em temperatura ambiente. Os sobrenadantes foram descartados e as massas celulares foram lavadas duas vezes com $\mathrm{NaCl}\left(1 \mathrm{~mol} . \mathrm{L}^{-1}\right)$, duas vezes com água destilada e centrifugadas após cada lavagem (PRABAKARAN; BALARAMAN, 2006). Após a última centrifugação, os precipitados foram fixados e secos em suportes metálicos e cobertos com partículas de ouro por 90 segundos, com uma corrente elétrica de $30 \mathrm{~mA}$, utilizando um metalizador Desk $\mathrm{V}^{\circledR}$
(Denton Vacuum, Nova Jersey, EUA). A microscopia eletrônica das amostras foi realizada sob baixo e alto vácuo de $10 \mathrm{a}$ $20 \mathrm{kV}$ em um microscópio eletrônico de varredura VEGA $3^{\circledR}$ (Tescan, Fuveau, França), no Centro de Apoio à Pesquisa da Universidade Federal Rural de Pernambuco.

\section{Análise estatística}

A determinação da concentração celular, a quantificação de delta-endotoxinas e esporos e a atividade proteásica foram apresentadas em valores médios e desvio padrão de dois experimentos independentes. Os dados foram analisados estatisticamente pelo Microsoft Excel 2010.

\section{Resultados e discussão}

\section{Avaliação da fermentação de Btb370 nos meios de cultura}

Por meio de análises da fermentação de Bacillus thuringiensis var. berliner cepa Bt370 (Btb370) em sete diferentes meios de cultura, pôde-se perceber que o meio à base do substrato de soro de leite sem suplementação de ureia 1 g.L.- (WM) foi o que indicou maiores resultados para o crescimento celular, produção de esporos e de delta-endotoxinas por Btb370 (Tabela 1). Içgen et al. (2002) também relataram que o soro de leite se apresentou como estimulante da formação de proteínas de cristal e da esporulação de B. thuringiensis. Além disso, WM foi o único substrato alternativo do presente trabalho que apresentou produção de delta-endotoxinas maior que o meio convencional LB, sendo este amplamente utilizado por outros pesquisadores para produzir toxinas por cepas de B. thuringiensis (ELLEUCH et al., 2015; JISHA et al., 2015; ZGHAL et al., 2018).

A adição de ureia $1 \mathrm{~g} . \mathrm{L}^{-1}$ no meio de cultura à base de soro de leite (WUM) não favoreceu o crescimento, a produção de delta-endotoxinas, esporos nem proteases por Btb370, apresentando, inclusive, resultados inferiores aos do WM (Tabela 1) e indicando que esse substrato não requer suplementação dessa fonte de nitrogênio. Esse fato pode ser justificado pela grande quantidade de proteínas no soro de leite, que provavelmente supre as necessidades de nitrogênio das bactérias em crescimento (LAGRANGE; CLARK, 2019).

Os meios de cultura à base de xarope de sorgo (SM; SUM) demonstraram resultados superiores ou similares ao meio LB em praticamente todas as análises, exceto na produção de delta-endotoxinas por Btb370 (Tabela 1). A adição de ureia 1 g.L. $\mathrm{L}^{-1}$ ao meio de sorgo (SUM) proporcionou aumento na concentração celular e produção de delta-endotoxinas e esporos por Btb370. Esse efeito pode ser devido à alta concentração de carboidratos no xarope de sorgo e à menor concentração de nitrogênio disponível para o desenvolvimento microbiano (RATNAVATHI et al., 2016), que foi mais bem suprida com a presença de ureia no meio.

Os meios de cultura à base de extrato de palma forrageira (PM; PUM) indicaram menor crescimento celular, menos esporulação e não apresentaram produção mensurável de delta-endotoxinas por Btb370 (Tabela 1). Além disso, a adição de ureia 1 g.L.- ${ }^{-1}$ no meio de cultura (PUM) não influenciou 
Tabela 1. Valores médios das análises de 96 horas de fermentação de Bacillus thuringiensis var. berliner (Btb370) em sete diferentes meios de cultura.

\begin{tabular}{|c|c|c|c|c|c|}
\hline Meio de cultura & $\begin{array}{c}\text { Densidade óptica } \\
(600 \mathrm{~nm})\end{array}$ & $\begin{array}{l}\text { Biomassa } \\
\left(\mathrm{g} . \mathrm{L}^{-1}\right)\end{array}$ & $\begin{array}{c}\text { Esporos } \\
\left(\mathbf{x} \mathbf{1 0}^{10} \mathrm{UFC}^{-\mathrm{mL}^{-1}}\right)\end{array}$ & $\begin{array}{l}\text { Delta-endotoxinas } \\
\left(\mathrm{mg} . \mathrm{L}^{-1}\right)\end{array}$ & $\begin{array}{l}\text { Proteases } \\
\left(\mathrm{U} . \mathrm{mL}^{-1}\right)\end{array}$ \\
\hline LB & $3,15 \pm 0,12$ & $1,75 \pm 0,76$ & $0,77 \pm 0,95$ & $450,98 \pm 60$ & $573,33 \pm 107$ \\
\hline PM & $1,05 \pm 0,63$ & $0,63 \pm 0,27$ & $0,22 \pm 0,55$ & 0 & $793,32 \pm 339$ \\
\hline PUM & $1,18 \pm 0,37$ & $0,48 \pm 0,25$ & $1,57 \pm 1,19$ & $\mathbf{0}$ & $4682,22 \pm 245$ \\
\hline SM & $2,87 \pm 0,09$ & $1,69 \pm 0,66$ & $7,95 \pm 0,7$ & $97,05 \pm 85$ & $6013,33 \pm 589$ \\
\hline SUM & $4,81 \pm 0,13$ & $2,34 \pm 0,35$ & $9,05 \pm 0,63$ & $180,41 \pm 86$ & $2915,55 \pm 576$ \\
\hline WM & $5,19 \pm 0,46$ & $4,28 \pm 0,28$ & $9,61 \pm 0,7$ & $568,26 \pm 74$ & $5962,22 \pm 405$ \\
\hline WUM & $3,48 \pm 0,82$ & $3,64 \pm 0,49$ & $4,18 \pm 0,53$ & $395,15 \pm 81$ & $2643,33 \pm 659$ \\
\hline
\end{tabular}

LB: Luria-Bertani; PM: extrato de palma forrageira; PUM: extrato de palma forrageira com ureia $1 \mathrm{~g} . \mathrm{L}^{-1}$; SM: xarope de sorgo; SUM: xarope de sorgo com ureia 1 g.L.-1 ${ }^{-1}$ WM: soro de leite; WUM: soro de leite com ureia 1 g.L ${ }^{-1}$.

o desenvolvimento do bacilo, com exceção da produção de proteases. Esse fato pode estar atrelado ao gênero da palma forrageira utilizada no presente trabalho, pois as palmas do gênero Opuntia são compostas, principalmente, de carboidratos pentose (xilose e arabinose) (TRACHTENBERG; MAYER, 1981), enquanto $B$. thuringiensis, preferencialmente, consome carboidratos hexose (MOUNSEF et al., 2014). Desse modo, a bactéria pôde ter apresentado dificuldades para desenvolver, esporular e produzir toxinas.

Não se verificou relação direta entre a esporulação e a produção de delta-endotoxinas de Btb370 no presente trabalho. A Figura 1 indica que mesmo com menor esporulação nos meios LB e WUM, houve significante produção de delta-endotoxinas, enquanto nos meios de cultura PUM, SM e SUM, apesar de terem apresentado considerável esporulação, não indicaram produção elevada de delta-endotoxinas, ou seja, o fato de Btb370 demonstrar elevada esporulação em determinado meio de cultura não significa, necessariamente, que também produzirá elevada quantidade de delta-endotoxinas ou vice-versa.

Corroborando o fato mencionado anteriormente, AbdelHameed et al. (1990) e Ennouri et al. (2013) também relatam que o crescimento celular e a esporulação nem sempre estão correlacionados com o rendimento de toxinas por $B$. thuringiensis. Assim, a produção de delta-endotoxinas é um parâmetro mais confiável para avaliar a eficiência do substrato como constituinte de meio de cultura Bt do que outros parâmetros.

\section{Relação entre proteases e delta-endotoxinas}

Assim como ocorreu entre a produção de esporos e de deltaendotoxinas, também não se observou um padrão positivo ou negativo entre a produção de proteases e de delta-endotoxinas por Btb370 no presente trabalho. A exemplo disso, a Figura 2 mostra que, para a maioria dos meios de cultura analisados, quando houve mais atividade proteásica, ocorreu diminuição da quantificação de delta-endotoxinas, podendo esse fato ser derivado de uma ação inibitória das proteases sobre as delta-endotoxinas, enquanto os meios à base de soro de leite apresentaram atividade proteásica tão alta quanto a produção de delta-endotoxinas, podendo isto se derivar de uma ação estimulante.

Uma possível justificativa para a diferença da influência das proteases sobre as delta-endotoxinas de Btb370 nos diferentes

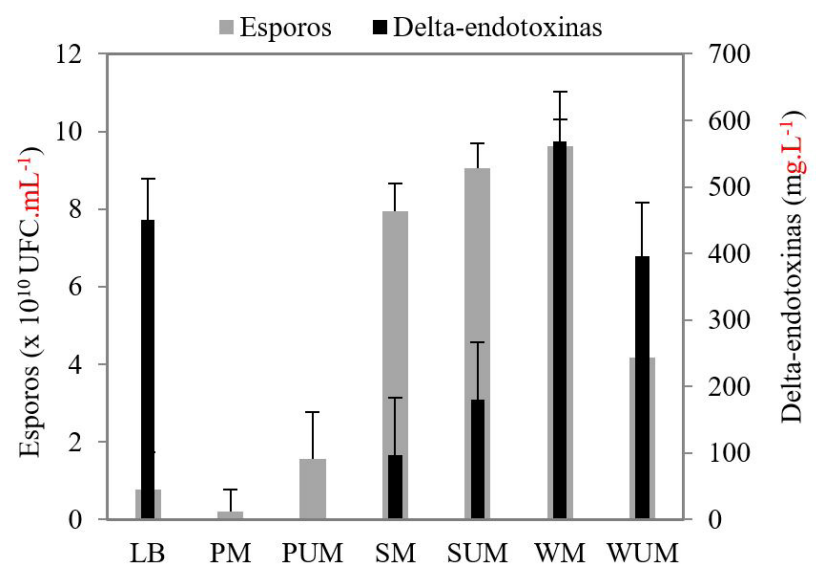

Figura 1. Relação entre a formação de esporos (x $10^{10}$ UFC.mL $\left.L^{-1}\right)$ e de delta-endotoxinas $\left(\mathrm{mg} . \mathrm{L}^{-1}\right)$ por Btb370 em sete diferentes meios de cultura após 96 horas de fermentação. LB: Luria-Bertani; PM: extrato de palma forrageira; PUM: extrato de palma forrageira com ureia $1 \mathrm{~g} . \mathrm{L}^{-1}$; SM: xarope de sorgo; SUM: xarope de sorgo com ureia 1 g.L-1 ${ }^{-1}$ WM: soro de leite; WUM: soro de leite com ureia 1 g.L-

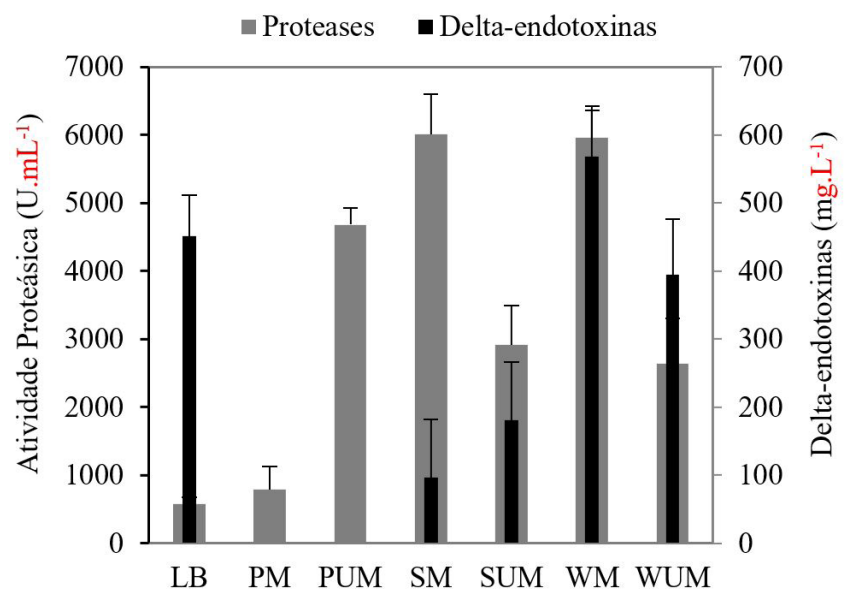

Figura 2. Relação entre a atividade proteásica (U.mL $L^{-1}$ ) e a produção de delta-endotoxinas $\left(\mathrm{mg} . \mathrm{L}^{-1}\right)$ por Btb370 em sete diferentes meios de cultura após 96 horas de fermentação. LB: Luria-Bertani; PM: extrato de palma forrageira; PUM: extrato de palma forrageira com ureia 1 g. $\mathrm{L}^{-1}$; SM: xarope de sorgo; SUM: xarope de sorgo com ureia 1 g.L.-1; WM: soro de leite; WUM: soro de leite com ureia 1 g.L $\mathrm{L}^{-1}$ 
meios de cultura estudados pode ser o fato de que a produção extracelular de proteases é fortemente influenciada pelos componentes do meio, como a variação na proporção $\mathrm{C} / \mathrm{N}$ e a presença de açúcares facilmente metabolizáveis, como glicose, e íons metálicos (BRAR et al., 2007).

Além disso, segundo Brar et al. (2007), as proteases de $B$. thuringiensis podem atuar de maneiras diferentes sobre as endotoxinas. Existem as proteases envolvidas na síntese de esporos e delta-endotoxinas de Bt, assim como na disponibilização de componentes proteicos para formação subsequente de esporos e toxinas de cristal, na lise celular e liberação de esporos maduros e proteínas de cristal, o que provocaria, consequentemente, um aumento do número de endotoxinas presentes no meio de cultura, podendo isto ter ocorrido nos meios à base de soro de leite. Por outro lado, existem proteases de $\mathrm{Bt}$ que promovem a degradação de protoxinas em pequenos fragmentos polipeptídicos, portanto diminuiriam o número de endotoxinas no meio de fermentação, fato que pode ter ocorrido com os demais meios de cultura estudados.

\section{Caracterização morfológica dos cristais proteicos de Btb370}

Foram selecionadas amostras no período de 96 horas de fermentação de Btb370 dos meios de cultura LB, SUM e WM para a análise morfológica dos cristais proteicos por meio do microscópio eletrônico de varredura (MEV), já que aqueles foram os meios que apresentaram produção razoável de delta-endotoxinas nesse período. Amostras do meio PUM às 96 horas também foram analisadas para verificar a presença ou não de cristais de Btb370.

De acordo com Schnepf et al. (1998), os cristais de Bt podem apresentar várias formas, como bipiramidal (Cry1), cuboidal (Cry2), retangular plano (Cry3A), irregular (Cry3B), esférico (Cry4A e Cry4B) e romboidal (Cry11A). Apesar de não ter sido identificada produção mensurável de delta-endotoxinas de Btb370 nos meios de cultura à base do extrato de palma forrageira, por meio do MEV se observou a presença de cristais esféricos, bipiramidais e cuboidais no meio PUM (Figura 3A), embora em quantidade inferior quando comparada às que ocorreram nos outros substratos.
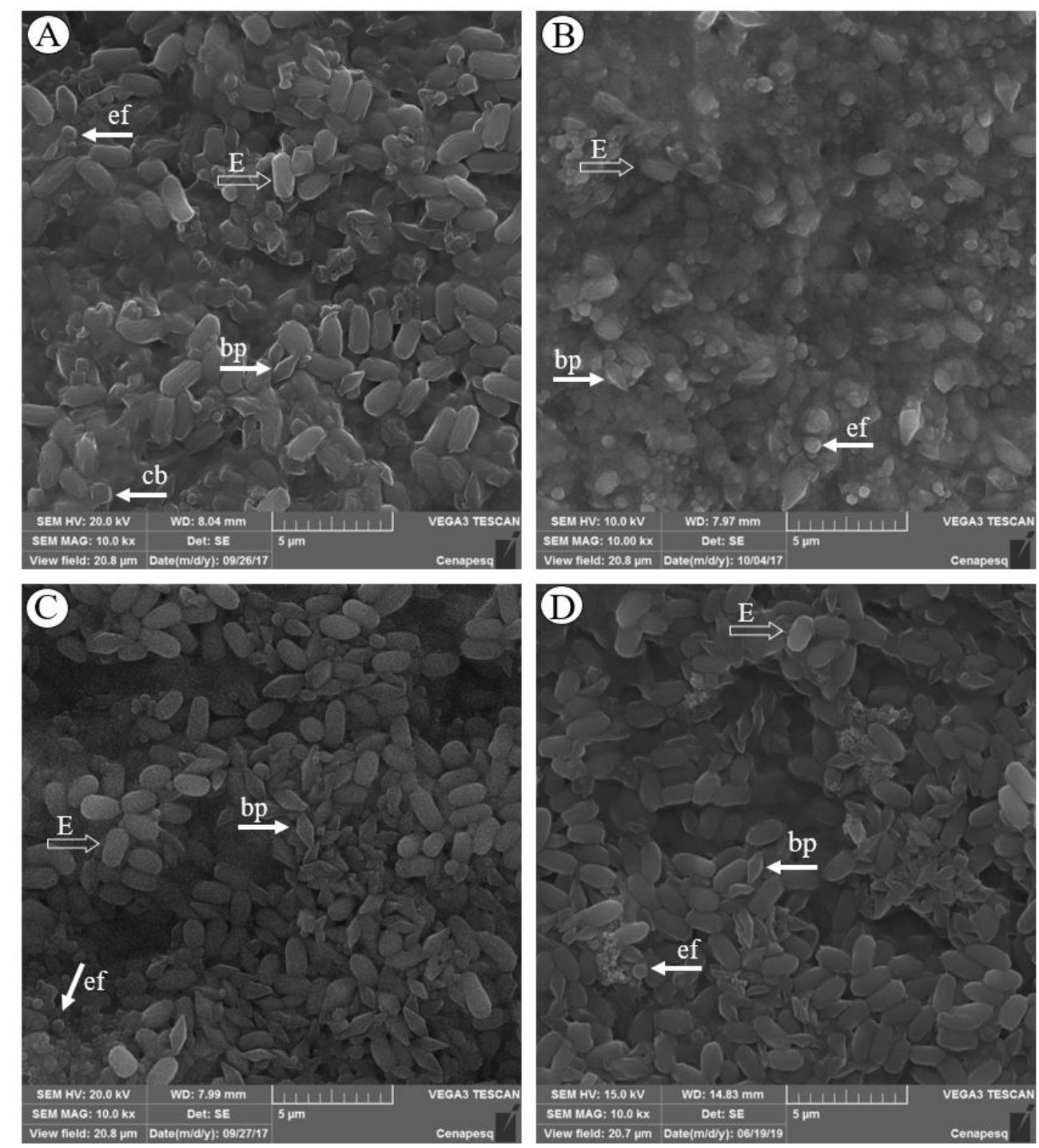

Figura 3. Microscopia eletrônica de varredura de Btb370 cultivado em extrato de palma forrageira com ureia 1 g.L-1 (A), Luria-Bertani (B), xarope de sorgo com ureia 1 g.L. $\mathrm{L}^{-1}$ (C) e soro de leite (D). E: esporos; BP: cristal bipiramidal; EF: cristal esférico; CB: cristal cuboidal. 
Corroborando as análises de quantificação de esporos e delta-endotoxinas produzidas por Btb370 mostradas na Figura 1, o meio LB apresentou poucos esporos e quantidade considerável de cristais esféricos e alguns bipiramidais (Figura 3B). Já os meios SUM (Figura 3C) e WM (Figura 3D) apresentaram quantidades significativas de esporos e delta-endotoxinas, com predominância de cristais bipiramidais e alguns esféricos.

A morfologia dos cristais bipiramidais foi a mais predominante na fermentação de Btb370. Da mesma forma, Bohorova et al. (1996) analisaram um total de 426 isolados de B. thuringiensis, tendo verificado que a maioria (84\%) mostrou a presença de cristais bipiramidais e quando a morfologia dos cristais de isolados mais ativos contra lepidópteros (Helicoverpa zea, Spodoptera frugiperda, Diatraea grandiosella e D. saccharalis) foi comparada, nenhuma morfologia específica foi associada à atividade e também não houve correlação entre os níveis de toxicidade e o tamanho do cristal.

\section{Conclusões}

Entre os substratos alternativos estudados, observou-se que o soro de leite sem suplementação de ureia 1 g.L $\mathrm{L}^{-1}$ foi o meio de cultura mais eficiente para o crescimento celular, produção de delta-endotoxinas, esporos e proteases por Bacillus thuringiensis var. berliner cepa Bt370 (Btb370), superando os resultados obtidos com o meio convencional Luria-Bertani, possibilitando, desta forma, a redução de custos para novas formulações de biocontroladores à base de Bt e para o acesso a proteases de importância industrial.

\section{Agradecimentos}

Os autores agradecem ao CNPq (Conselho Nacional de Desenvolvimento Científico e Tecnológico) a Bolsa de Produtividade em Pesquisa, 305719/2016-5, e a bolsa de pós-doutorado, PDJ-152774/2018-1. Agradecem à Facepe (Fundação de Apoio à Ciência e Tecnologia de Pernambuco) a bolsa de iniciação à pesquisa BIC-0912-2.12/17 e a bolsa de mestrado, IBPG-0475-5.05/17. Este estudo foi apoiado pela bolsa Facepe "Projeto Institucional Pesquisador Visitante" (SIN-0156-5.01/17) e Bolsa Universal MCTIC do CNPq (426192/2018-4).

\section{Referências}

Abdel-Hameed, A.; Carlberg, G., E1-TAYEB, O. M. Studies on Bacillus thuringiensis H-14 strains isolated in Egypt-III. Selection of media for $\delta$-endotoxin production. World Journal of Microbiology \& Biotechnology, Oxford, v. 6, p. 313-317, 1990. http://dx.doi. org/10.1007/BF01201303.

Adang, M. J.; Crickmore, N.; Jurat-Fuentes, J. L. Diversity of Bacillus thuringiensis crystal toxins and mechanism of action. Advances in Insect Physiology, San Diego, v. 47, p. 39-87, 2014. http://dx.doi. org/10.1016/B978-0-12-800197-4.00002-6.

Alencar, R. B. et al. Alkaline proteases from digestive tract of four tropical fishes. Brazilian Journal of Food Technology, Campinas, v. 6, p. 279-284, 2003.
Annamalai, N. et al. Optimization, purification and characterization of novel thermostable, haloalkaline, solvent stable protease from Bacillus halodurans CAS6 using marine shellfish wastes: a potential additive for detergent and antioxidant synthesis. Bioprocess and Biosystems Engineering, Berlin, v. 36, p. 873-883, 2013. http:// dx.doi.org/10.1007/s00449-012-0820-3 .

Bohorova, N. et al. Selection and characterization of Mexican strains of Bacillus thuringiensis active against four major lepidopteran maize pests. Entomophaga, Paris, v. 41, n. 2, p. 153-165, 1996. http://dx.doi.org/10.1007/BF02764243.

Bougatef, A. et al. Protein hydrolysates from Bluefin Tuna (Thunnus thynnus) heads as influenced by the extent of enzymatic hydrolysis. Biotechnology and Bioprocess Engineering, South Korea, v. 17, p. 841-852, 2012. http://dx.doi.org/10.1007/s12257-012-0053-y.

Brar, S. K. et al. Bacillus thuringiensis proteases: production and role in growth, sporulation and synergism. Process Biochemistry, London, v. 42, p. 773-790, 2007. http://dx.doi.org/10.1016/j. procbio.2007.01.015.

Caille, J. et al. Hetero diels-alder-biocatalysis approach for the synthesis of (S)-3-[2-\{(Methylsulfonyl) oxy\} ethoxy]-4-(triphenylmethoxy)1-butanol Methanesulfonate, a key intermediate for the synthesis of the PKC inhibitor LY333531. Organic Process Research \& Development, Washington, v. 6, n. 4, p. 471-476, 2002. http:// dx.doi.org/10.1021/op020202a.

Elleuch, J. et al. Characterisation of novel Bacillus thuringiensis isolates against Aedes aegypti (Diptera: Culicidae) and Ceratitis capitata (Diptera: Tephridae). Journal of Invertebrate Pathology, San Diego, v. 124, p. 90-97, 2015. http://dx.doi.org/10.1016/j. jip.2014.11.005.

Ennouri, K. et al. Correlation between delta-endotoxin and proteolytic activities produced by Bacillus thuringiensis var. kurstaki growing in an economic production medium. Biocontrol Science and Technology, Oxford, v. 23, n. 7, p. 756-767, 2013. http://dx.doi. org/10.1080/09583157.2013.791364.

Fox, P. F. et al. Fundamentals of cheese science. 2nd ed. New York: Springer, 2017. $816 \mathrm{p}$.

Frota, M. N. L. et al. Palma forrageira na alimentação animal. 1. ed. Teresina: Embrapa Meio-Norte, 2015. 47 p.

Içgen, Y.; Içgen, B.; Ozcengiz, G. Regulation of crystal protein biosynthesis by Bacillus thuringiensis: II. Effects of carbon and nitrogen sources. Research in Microbiology, Paris, v. 153, p. 605-609, 2002. http://dx.doi.org/10.1016/s0923-2508(02)01366-9.

Jisha, V. N. et al. Biphasic fermentation is an efficient strategy for the overproduction of $\delta$-endotoxin from Bacillus thuringiensis. Applied Biochemistry and Biotechnology, Clifton, v. 175, p. 1519-1535, 2015. http://dx.doi.org/10.1007/s12010-014-1383-3.

Lagrange, V.; Clark, D. C. Nutritive and therapeutic aspects of whey proteins. In: DEETH, H. C.; BANSAL, N. Whey Proteins: From Milk to Medicine. London: Academic Press, 2019. p. 549-577.

Melgar, R.; Camozzi, M. E.; Figueroa, M. M. Nitrogenados. In: MELGAR, R.; CAMOZZI, M. E.; FIGUEROA, M. M (Org.) Guía de fertilizantes, enmiendas y productos nutricionales. Buenos Aires: Instituto Nacional de Tecnología Agropecuária, 1999. p. 13-25.

Mounsef, J. R. et al. Evaluation of a cereal milling by-product for the low cost production of Bacillus thuringiensis kurstaki in submerged fermentation. European Journal of Biotechnology and Bioscience, Delhi, v. 1, n. 6, p. 10-16, 2014.

Ozcan, T.; Kurdal, E. The effects of using a starter culture, lipase, and protease enzymes on ripening of Mihalic cheese. International 
Journal of Dairy Technology, Huntingdon, v. 65, p. 585-593, 2012. http://dx.doi.org/10.1111/j.1471-0307.2012.00868.x.

Pan, X. et al. Biosorption and extraction of europium by Bacillus thuringiensis strain. Inorganic Chemistry Communications, New York, v. 75, p. 21-24, 2017. http://dx.doi.org/10.1016/j.inoche.2016.11.012.

Prabakaran, G.; Balaraman, K. Development of a cost-effective medium for the large scale production of Bacillus thuringiensis var. israelensis. Biological Control, Orlando, v. 36, p. 288-292, 2006. http://dx.doi.org/10.1016/j.biocontrol.2005.09.018.

Ratnavathi, C. V.; Patil, J. V.; Chavan, U. D. Sorghum biochemistry: an industrial perspective. London: Academic Press, 2016. 253 p.

Raymond, B. et al. Bacillus thuringiensis: an impotent pathogen? Trends in Microbiology, Cambridge, v. 18, p. 189-194, 2010. http://dx.doi.org/10.1016/j.tim.2010.02.006.
Schnepf, E. et al. Bacillus thuringiensis and its pesticidal crystal proteins. Microbiology and Molecular Biology Reviews, New York, v. 62, p. 775-806, 1998.

Shojaaddini, M. et al. Development of a cost effective medium for production of Bacillus thuringiensis bioinsecticide using food barley. Journal of Plant Protection Research, Poznań, v. 50, n. 1, p. 9-14, 2010. http://dx.doi.org/10.2478/v10045-010-0002-8.

Trachtenberg, S.; Mayer, A. M. Composition and properties of Opuntia ficus-indica mucilage. Phytochemistry, v. 20, n. 12, p. 2665-2668, 1981. http://dx.doi.org/10.1016/0031-9422(81)85263-6.

Zghal, R. Z. et al. Optimization of bio-insecticide production by Tunisian Bacillus thuringiensis israelensis and its application in the field. Biological Control, Orlando, v. 124, p. 46-52, 2018. http:// dx.doi.org/10.1016/j.biocontrol.2018.06.002.

Recebido: 25 jun. 2020 Aprovado: 09 set. 2020 